\title{
Microstructural Evolution in the 2219 Aluminum Alloy During Severe Plastic Deformation
}

R.O. Kaibyshev, I.M. Safarov, D.R. Lesuer

U.S. Department of Energy

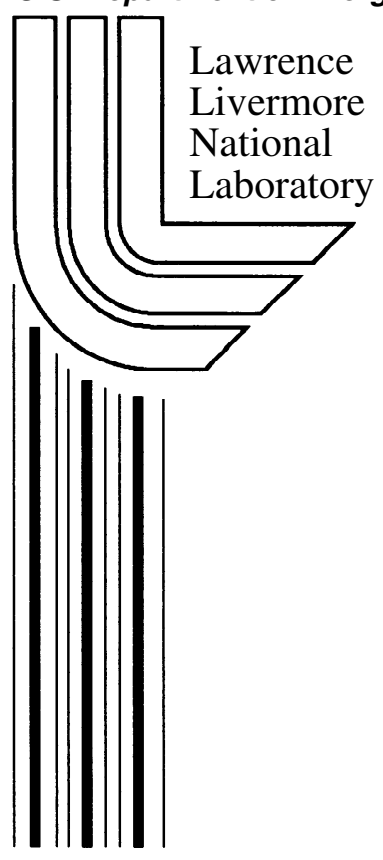

March 29, 2000 


\section{DISCLAIMER}

This document was prepared as an account of work sponsored by an agency of the United States Government. Neither the United States Government nor the University of California nor any of their employees, makes any warranty, express or implied, or assumes any legal liability or responsibility for the accuracy, completeness, or usefulness of any information, apparatus, product, or process disclosed, or represents that its use would not infringe privately owned rights. Reference herein to any specific commercial product, process, or service by trade name, trademark, manufacturer, or otherwise, does not necessarily constitute or imply its endorsement, recommendation, or favoring by the United States Government or the University of California. The views and opinions of authors expressed herein do not necessarily state or reflect those of the United States Government or the University of California, and shall not be used for advertising or product endorsement purposes.

Work performed under the auspices of the U. S. Department of Energy by the University of California Lawrence Livermore National Laboratory under Contract W-7405-Eng-48.

This report has been reproduced directly from the best available copy.

Available to DOE and DOE contractors from the

Office of Scientific and Technical Information

P.O. Box 62, Oak Ridge, TN 37831

Prices available from (423) 576-8401

http://apollo.osti.gov/bridge/

Available to the public from the National Technical Information Service

U.S. Department of Commerce 5285 Port Royal Rd., Springfield, VA 22161 http://www.ntis.gov/

OR Lawrence Livermore National Laboratory Technical Information Department's Digital Library http://www.llnl.gov/tid/Library.html 


\title{
MICROSTRUCTURAL EVOLUTION IN THE 2219 ALUMINUM ALLOY DURING SEVERE PLASTIC DEFORMATION
}

\author{
R.O. Kaibyshev ${ }^{1}$, I.M.Safarov ${ }^{1}$, D.R.Lesuer ${ }^{2}$ \\ ${ }^{1}$ Institute for Metals Superplasticity Problems, Khalturina 39, Ufa 450001, Russia \\ ${ }^{2}$ Lawrence Livermore National Laboratory, L-342 P.O. Box 808, Livermore, CA 94551, USA
}

Keywords: microstructural evolution, severe plastic deformation, cell structure, dislocation rich bands, nanocrystalline structure.

\section{$\underline{\text { Introduction }}$}

Numerous investigations have demonstrated that intense plastic deformation is an attractive procedure for producing an ultrafine grain size in metallic materials. Torsional deformation under high pressure [1] and equal-channel angular extrusion [2] are two techniques that can produce microstructures with grain sizes in the submicrometer and nanometer range. Materials with these microstructures have many attractive properties. The microstructures formed by these two processing techniques are essentially the same and thus the processes occurring during deformation should be the same.

Most previous studies have examined the final microstructures produced as a result of severe plastic deformation and the resulting properties. Only a limited number of studies have examined the evolution of microstructure [3-6]. As a result, some important aspects of ultra-fine grain formation during severe plastic deformation remain unknown. There is also limited data on the influence of the initial state of the material on the microstructural evolution and mechanisms of ultrafine grain formation. This limited knowledge base makes optimization of processing routes difficult and retards commercial application of these techniques.

The objective of the present work is to examine the microstructure evolution during severe plastic deformation of a 2219 aluminum alloy. Specific attention is given to the mechanism of ultrafine grain formation as a result of severe plastic deformation.

\section{Materials and Experimental Technique}

The 2219 aluminum alloy with the chemical composition Al-6.4\% $\mathrm{Cu}-0.3 \% \mathrm{Mn}-0.18 \% \mathrm{Cr}-0.19 \% \mathrm{Zr}-$ $0.06 \% \mathrm{Fe}$ was cast at the Kaiser Aluminum - Center for Technology by direct chill casting. The alloy was then homogenized at $530^{\circ} \mathrm{C}$ for 6 hours. Two states of the alloy (coarse and fine grained) were used in present study. The coarse grained material had an initial size about $118 \mu \mathrm{m}$ (state 1) and was produced by water quenching of the cast ingot from the standard homogenization temperature. The fine grained material had an initial grain size about $10 \mu \mathrm{m}$ (state 2) and was produced by a 
thermomechanical process. Samples were annealed at $500^{\circ} \mathrm{C}$ in a furnace for one hour and slow cooled after thermomechanical processing.

The microstructural evolution of the 2219 aluminum alloy during severe plastic deformation was evaluated in torsion using the Bridgeman anvil technique [1]. Torsion samples, which were prepared from both states of the material, had a diameter of $8 \mathrm{~mm}$ and a thickness of $0.3 \mathrm{~mm}$. These samples were deformed at ambient temperature and a pressure of $5 \mathrm{GPa}$ was applied during torsional deformation. True strain $\varepsilon$ was estimated by use of the expression

$$
\varepsilon=\ln (\phi \mathrm{d} / 2 \mathrm{a})
$$

where $\phi$ is an angular displacement, $d$ is the diameter of the tested sample and a is the thickness. The microhardness of the samples after various increments in torsional strain was evaluated using a PMT-3 device with a load of $20 \mathrm{~g}$ on Vickers diamond pyramid intentor. Samples were also examined using TEM. For these examinations, discs $3 \mathrm{~mm}$ in diameter were cut from the samples and then electropolished in a Tenupol-3 twin-jet polishing unit using a standard $30 \% \mathrm{CH}_{3} \mathrm{COOH}+70 \% \mathrm{HNO}_{3}$ solution at $-30^{\circ} \mathrm{C}$. The thin foils were examined using a Jeol-2000EX TEM and a double-tilt stage with an accelerating potential of $200 \mathrm{kV}$. X-ray analysis was performed using a DRON-4 device. The coherent domain size and internal elastic strain were determined using the Williamson-Hall method.

\section{Results}

The microhardness of the as-processed samples is shown in Fig. 1 as a function of strain. Up to $\varepsilon=0.5$, the results show that, for both states of the material, plastic deformation does not produce significant increases in the hardness of the 2219 alloy. In the range $\varepsilon=0.5-2$, the microhardness increases by approximately a factor of two. Above $\varepsilon=2$, the microhardness increases gradually with the microhardness of state 2 increasing faster than the hardness of state 1 . At $\varepsilon \leq 4$, state 1 has a greater hardness than state 2 ; by $\varepsilon=7$, the higher rate of increase in the hardness of state 2 causes the two states to have comparable microhardnesses.

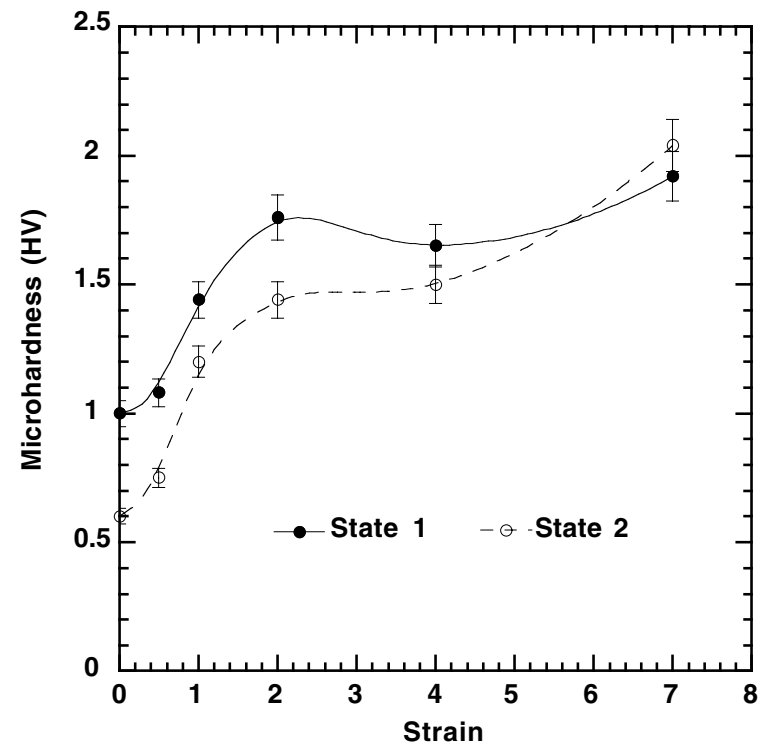

Fig.1. Microhardness vs. strain for the two states of the 2219 aluminum alloy. 
The results of the X-ray line broadening analysis are presented in Fig. 2 for strains greater than $\varepsilon=0.5$. Both the coherent domain size and the internal elastic strain decrease with increasing strain. The largest decrease in both these quantities occurs in the strain range $\varepsilon=0.5-1$. At a strain of $\varepsilon=1$, the coherent domain size has decreased to $0.09 \mu \mathrm{m}$ for the material in state 1 and $0.15 \mu \mathrm{m}$ for the material in state 2. Relatively insignificant reductions in coherent domain size and internal elastic strain occur at strains larger than $\varepsilon=1$.

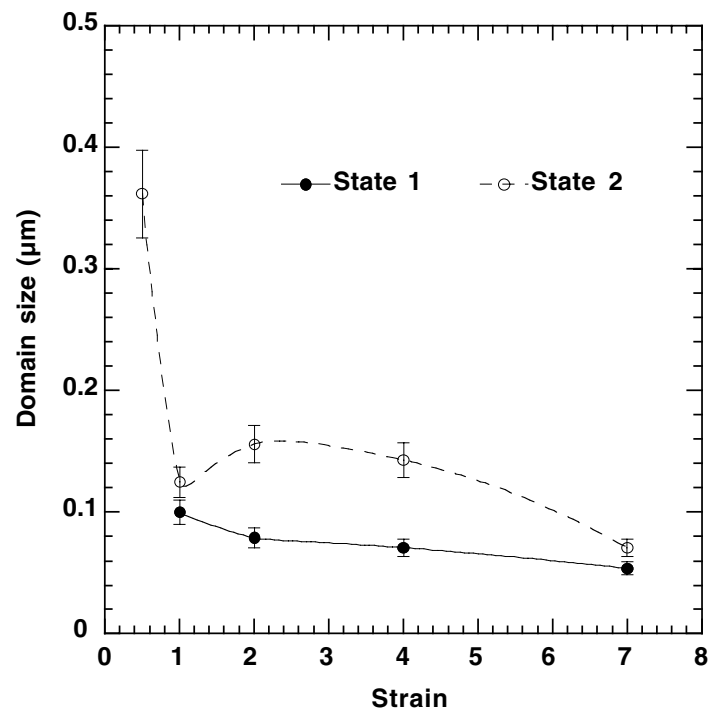

(a)

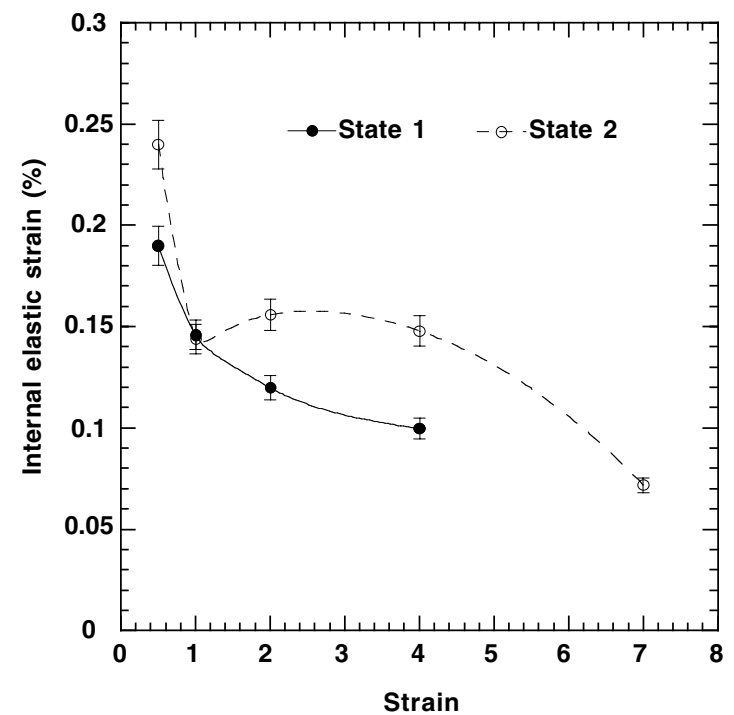

(b)

Fig.2. Coherent domain size (a) and internal elastic strain (b) vs. strain for the two states of the 2219 aluminum alloy.

Examination of the deformed samples using TEM showed that after a strain of $\varepsilon=0.5$ a cell structure had developed (Fig. 3a). This cell structure was observed for both states of the material and consisted of cells bounded by banded areas of uniform diffraction contrast containing a high density of lattice dislocations. These volume elements had an average size of about $1 \mu \mathrm{m}$ and a boundary thickness of about $500 \mathrm{~nm}$. Inside the cells, tangled dislocations were observed with a lower dislocation density than in the boundaries. Diffraction analysis revealed spots that were elongated in the azimuthal direction by $1-3^{0}$. These elongated spots are indicative of continuous misorientations in the cell structure. Increasing plastic deformation produces a change in the cell structure. The conventional cell structure [7] transforms into a lamellar band (LB) structure [8]. This lamellar structure consists of misoriented high density dislocation bands. This structure is similar to the cell block structure reported by Bay et al. [7] and Hughes and Hansen [8]. In addition, there were highly misorientated areas within the LBs. Observation of Moire patterns inside of the LBs also indicated that progressive misorientation exists within the bands. It was evident from diffraction contrast that there was misorientation between a LB boundary and LB body. A reduction of the LB boundary thickness to about $300 \mathrm{~nm}$ (Fig. 3b) was observed at $\varepsilon=1$ relative to cell boundary thickness at $\mathrm{e}=0.5$. In addition the dislocation density within the cells was observed to be higher than the dislocation density at $\varepsilon=0.5$. The dislocation density within the LBs increased in comparison with cell structure and produced misorientation between LBs. Elongation of the diffraction spots increased to $5-7^{0}$. After deformation of the state 1 samples to a strain of $\varepsilon=2$ (or the state 2 samples to a strain of $\varepsilon=4)$, the TEM examinations revealed that individual crystallites had formed with high-angle grain boundaries (Fig. 3c). These high angle boundaries are produced from the 
dislocation-rich bands and exhibit nonuniform contrast. The ultrafine grains produced have an irregular shape and, as previously observed in Al-Mg solid solution alloys, the grain boundaries have a nonequilibrium configuration [9]. The dislocation density inside the grains was low. Increasing plastic deformation resulted in an increase in the volume fraction of nanoscale grains and an increase in the number of triple junctions and lower energy grain boundary configurations. After a strain of $\varepsilon=7$, the grains had a large number of triple junctions and equiaxed shapes (Fig. 3d).

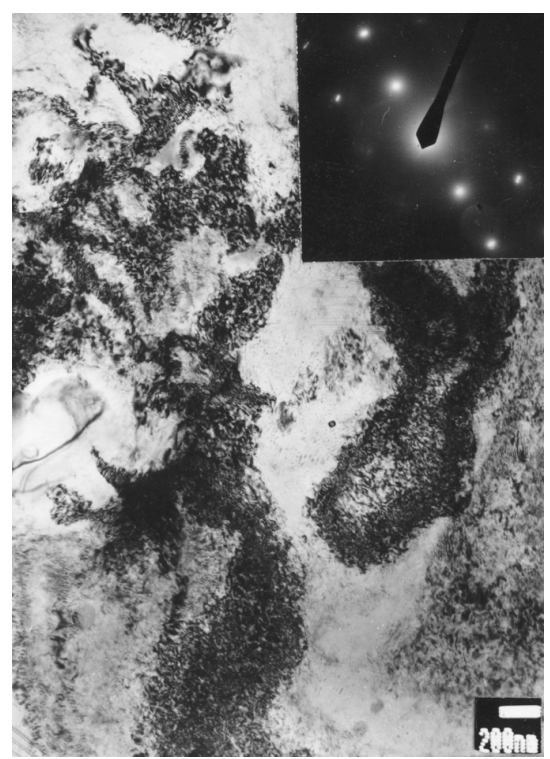

(a)

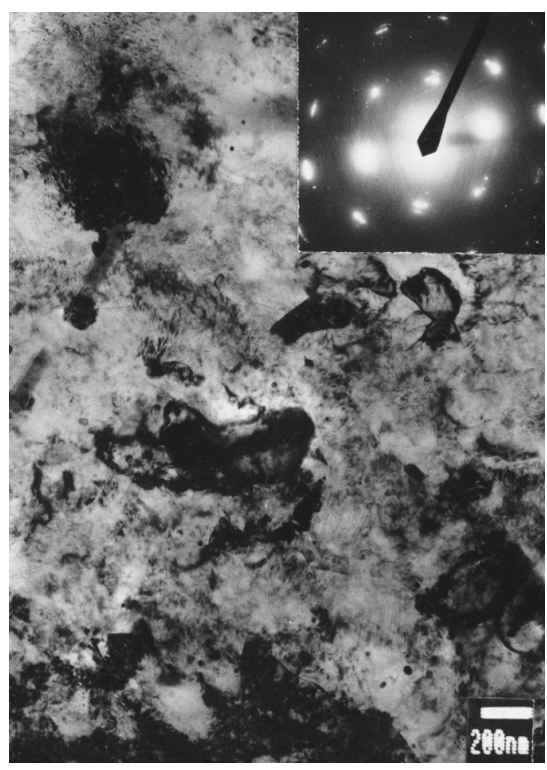

(c)

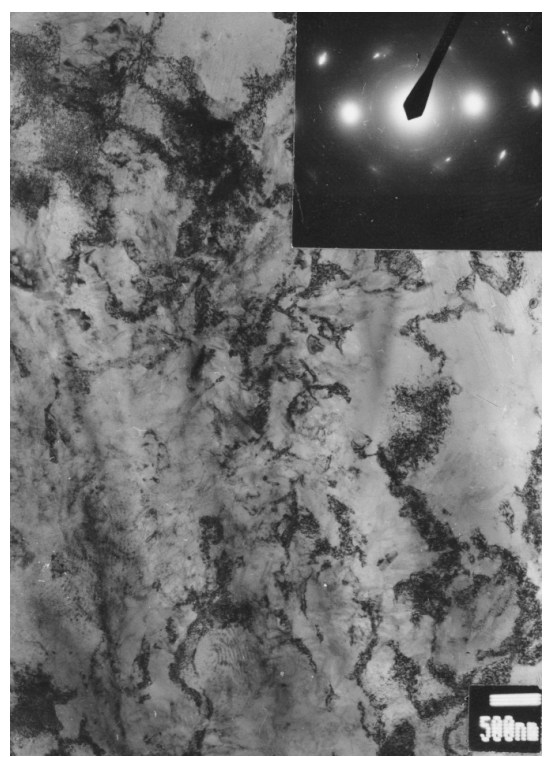

(b)

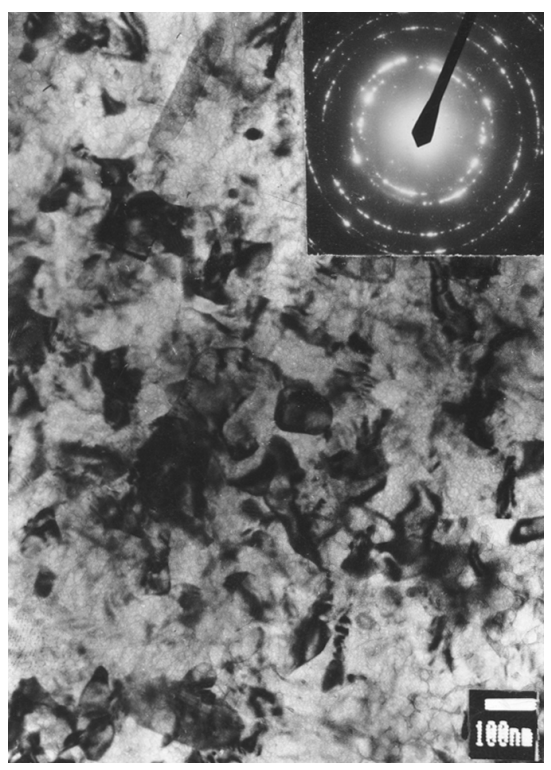

(d)

Figure 3. Microstructure of the severe strained A12219 alloy a) state 2, $\varepsilon=0.5$, b) state 1, $\varepsilon=1$, c)state 1, $\varepsilon=2$, d) state $1 \varepsilon=7$.

The microstructural evolution studies reported here show that the formation of a nanoscale structure occurs with less strain for the quenched, coarse grained material (state 1) than for the fine grained material (state 2). For the state 1 material, after a strain of $\varepsilon=7$, approximately $90 \%$ of the grains have sizes in the nanometer range. After a strain of $\varepsilon=7$, the average grain size of the 
material processed from both states is about $120 \mathrm{~nm}$. These values are very close to the coherent domain sizes measured by the X-ray technique.

\section{$\underline{\text { Discussion }}$}

The results in the previous section show that microstructural evolution during intense torsional straining of the 2219 alloy takes place in four stages. In stage one (observed at $\varepsilon=0-0.5$ ), the lattice dislocation density increases and a cell structure begins to form. The microstructure at a strain of $\varepsilon=0.5$ is shown schematically in Fig. 4a. The development of this microstructure is accompanied by an increase in microhardness and internal elastic strain. In stage $2(\varepsilon=0.5-1.0)$, extensive dislocation accumulation take place in bands which results in the formation of new LBs (Fig. 4b). These bands are subdivided into misorientated dislocation areas which become the nuclei for new nanometer grains. With increasing strain in stage 2, the cell block size decreases and the coherent domain size drops to about $100 \mathrm{~nm}$ at the end of stage 2. Notably, the coherent domain size matches the size of the misorientated areas with high dislocation density. These microstructural changes are accompanied by an increase in hardness and a decrease in internal elastic energy due to the reduction of free dislocation energy via the formation of a lower-energy dislocation structure. In stage 3 ( $\varepsilon=$ 1.0 - 4.0), dislocation rearrangements provide a progressive rotation into the dislocation rich bands resulting in the formation of nanoscale grains. Growth of boundary misorientations and conversion of dislocation boundaries into high-angled boundaries takes place (Fig. 4c). Internal elastic strain tends to decrease in the quenched state of the 2219 alloy (state 1) and is essentially stable relative to the state produced by thermo-mechanical processing (state 2). This is caused by the fact that grain structure formation is easier for the material in state 1 and thus the resulting grain size is smaller relative to state 2 . In stage four $(\varepsilon=4.0-7.0)$, the shape of the nanoscale grains becomes equiaxed and triple points are observed in the microstructure (Fig. 4d). A well-defined granular structure forms during this stage of plastic flow. Partial dislocation absorption occurs within the boundaries of these grains. These microstructural changes cause a minor increase in microhardness despite decreases in the lattice dislocation density and internal elastic strain.

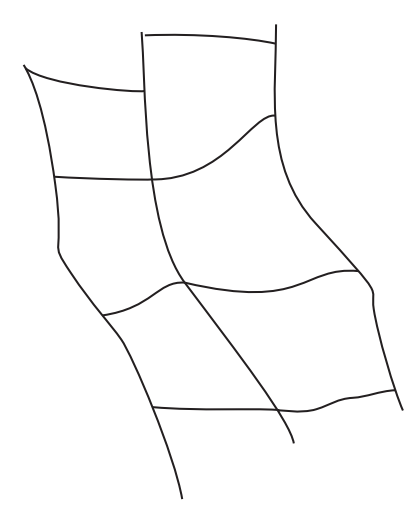

$$
\varepsilon=0.5
$$
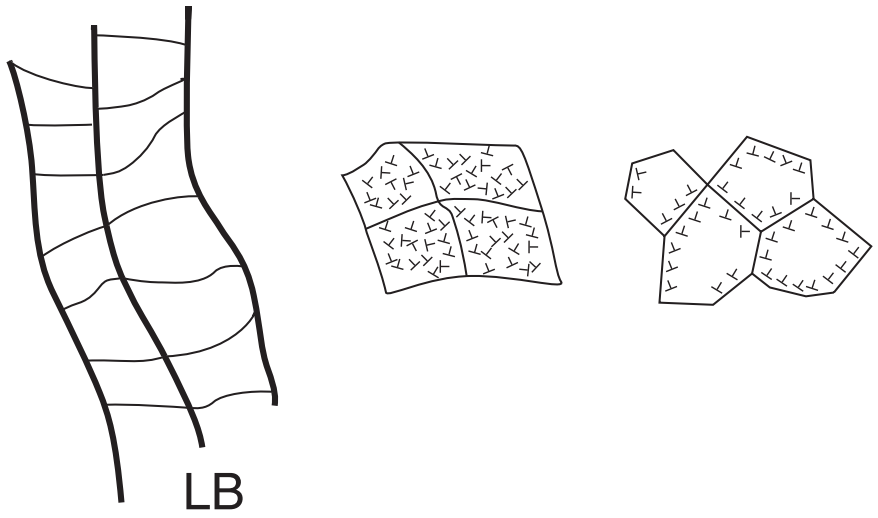

$\varepsilon=4.0$ $\varepsilon=7.0$

Figure 4. Schematic illustration of microstructural evolution in the 2219 alloy, a) cell formation at $\varepsilon=0.5$, b) lamellar dislocation-rich bands containing misorientated areas at $\varepsilon=1$, c) formation of crystallites with irregular shape and enhanced density of lattice dislocations, d) formation of nanoscale grains with non-equilibrium boundaries. 
Thus during severe plastic deformation, the ultrafine-grained microstructures develop as a result of the gradual evolution of the dislocation substructure. At moderate strains, the spatial distribution of lattice dislocations forms a low energy cell structure. With increasing strain, this cell structure transforms into an LB structure. At large strains, dislocation boundaries are converted into high angle boundaries and the cellular structure transforms into an nanoscale-grained structure. For state 1 of the 2219 alloy, each stage in the microstructural evolution process is accompanied by a decrease in internal elastic strain

The results in the previous section also show important differences in microstructural evolution for the 2219 alloy in states 1 and 2. State 1 is characterized by a supersaturated solid solution and thus higher elastic strains in the initial structure. The stresses associated with the elastic strain fields help to promote the formation of nanoscale grains through their interaction with the long range stresses originating from the nonequilibrium boundaries. As a result, new ultrafine grains form at smaller strains for material in state 1 as opposed to state 2 . The presence of a supersaturated solid solution is beneficial for the formation of a nanoscale microstructure.

\section{$\underline{\text { Acknowledgments }}$}

The authors thank Mr. I. Kazakulov for assistance in sample preparation for intense plastic straining. Discussions with Dr. Chol Syn are gratefully acknowledged. This work was performed under the auspices of the U.S. Department of Energy by the Lawrence Livermore National Laboratory under contract No. W-7405-ENG-48.

\section{References}

1. N.A. Smirnova, V.I.Levit, V.I.Pilyugin, R.I.Kuznetsov, L.S.Davydova, V.A.Sazonov, Phys. Met. Metall., 61,1170, (1986), (in Russian).

2. V.M.Segal, Mater. Sci. Eng., A197, 157 (1995).

3. A.N.Belyakov, R.O.Kaibyshev. Nano Struct. Mat., 6, 893 (1995).

4. R.Kaibyshev, O.Sitdikov. Z. Metallkunde, B85, 738, (1994).

5. Y.Iwahashi, Z.Horita, M.Nemoto, T.Langdon, Acta Mater., 46, 3317 (1998).

6. R. Valiev, Yu.Inanesenko, E,F.Rauch. Acta Metall. Mater 44, 4705 (1996).

7. B.Bay, N.Hansen, D.Hughes, D.Kuhlmann-Wilsdorf, Acta Met. Mater., 40, 205 (1992).

8. D.Hughes, N.Hansen, Acta Met. Mater., 45, 3871 (1997).

9. Z.Horita, D.Smith, M.Furukawa, M.Nemoto, R.Valiev, T.Langdon, J. Mater. Res., 11, 1880 (1996). 